\title{
NATIONAL RESEARCH COUNCIL OF CANADA
}

\section{REPORT FOR 1956-57}

$\mathrm{T}$ HE annual report of the National Research Council of Canada for the year 1956-57* has recently been received. Besides the reports of the president, Dr. E. W. R. Steacie, and the financial statement, it comprises accounts of the work of the two regional laboratories and of the several Divisions, including that of Administration and Awards, through which some $3 \cdot 6$ million dollars were allocated during the year in support of pure research in the universities. This expenditure included 540 grants and 310 scholarships and fellowships. The Senior Medical Research Fellowships offered during the past seven years have been replaced by Medical Research Associateships. Besides the information services maintained by the Division, it was responsible for publishing seven scientific periodicals, but with the issue of The Canadian Journal of Technology for March 1957 the Council discontinued publication of that journal.

The president's report briefly reviews the development of the work of the Council during the past forty years. The Council's scientific staff now num. bers 541, including 122 postdoctorate fellows, its technical staff 819 and general service and administrative 859, while its twenty-six associate committees cover such diverse fields as aquatic biology, corrosion research, plant breeding, radio science and soil and snow mechanics. Some 7,600 technical inquiries from Canadian industries were handled during the year.

The Division of Applied Biology has made tests to obtain basic design and process information on liquid immersion freezing of poultry, and its freezing studies on milk are providing further information on the effect of cooling and freezing on the association of enzymes with particulate matter of living cells. The structure, properties and behaviour of hemicelluloses of common pulping woods are being determined to assist in the solution of manufacturing problems in using the new semi-chemical pulps. Studies of the alga Microcystis aeruginosa indicated that two out of nine strains were highly toxic and twelve other species or strains of algae that were suspect were essentially non-toxic. Studies of the effect of different bacteria on casein indicated that lactobacilli normally found in dairy products could utilize sodium caseinate, while lactobacilli from other sources could not. The Atlantic Regional Laboratory, Halifax, continued its studies on storage of potatoes, drying of rockweed, and deposition of pitch from sulphite pulp mills in the Atlantic Provinces, and has also completed a systematic survey of the chemical composition of peat from some of the larger bogs in the Atlantic Provinces.

Fundamental investigations at the Prairie Regional Laboratory, Saskatoon, include studies on the properties and reactions of starches, sugars, proteins, fats and oils; the physiology and biochemistry of living plants and micro-organisms; and the production of protein feed supplements by growing

- Fortieth Annual Report of the National Research Council of Canada, 1956-57 (including the Annual Report of Canadian Patents Queen's Printer, 1957.) micro-organisms on waste sulphite liquor or molasses media.

In the Division of Applied Chemistry, fundamental studies on semiconducting oxide catalysts and on the surface properties of selected single crystals of silver have led to a better understanding of dehydrogenation and of oxidation of hydrocarbon molecules. Pilot-plant studies of the ethylene oxide process continued, and the application of spouted-bed technique to industrial drying problems has been investigated. Values have been obtained for heat and entropy changes during the catalysed reversible polymerization of $\alpha$-methylstyrene and partial molar heats of solution at infinite dilution have been calculated for an alloy system by means of a simple Sommerfeld model. A study of the reaction of butene with anhydrous perchloric acid indicated that that acidalone does not cause polymerization. Some chemical fungicides promoted chemical degradation of cotton through hydrolysis or actinic breakdown of the compound. The Division of Pure Chemistry reports progress in determining the structure of several alkaloids, and further work on the vapour-phase photolysis of organic compounds has been concerned mainly with ketones (including those fully substituted with deuterium or fluorine), azo compounds, esters and peroxides, while the free radicals produced in the mercury photo-sensitized decompositions of acetone, acetaldehyde and $1: 2$ - and $1: 3$-butadiene have been detected and identified and the nature and relative probability of the various modes of dissociation determined. Comprehensive measurements of specific heat have been completed for a series of alkali halide crystals and a solution calorimeter with an improved adiabatic control has been used to determine the heats of dilution of aqueous detergents. In studies of intermolecular forces which have led to a better understanding of the behaviour of molecules containing unsaturation electrons ( $\pi$-electrons), nuclear magnetic resonance has proved valuable.

The Division of Applied Physics reports difficulty in recruiting first-class personnel, but in heat and solid state physics, $X$-rays and nuclear radiations and photogrammetry, its work continued to expand. In acoustics ear-defenders have now been combined with earphones to give greater signal-to-noise ratios and grestly improved low-frequency sensitivity and more uniform response. A new cæsium resonator has been constructed which will not be influenced by the casual disturbances that affect the mechanical vibrations of quartz oscillators. A high-temperature laboratory equipped to measure electrical and thermal conductivities up to $2,400^{\circ} \mathrm{C}$. is being established. A comprehensive investigation of aerial triangulation has been begun, the method developed for analytical aerial triangulation yielding very valuable information. In the Division of Pure Physics the cosmic-ray group set up two new observing stations, one at Churchill, and the other on top of Sulphur Mountain, near Banff. Investigations continued on the behaviour of energetic nuclear particles when penetrating matter, and new spectra of chemically unstable 
molecules have boen obtained by the flash photolysis technique. The hyperfine structures of the ground states of both stable isotopes of copper have been investigated by the atomic-beam magnetic-resonance method and the hyperfine structure anomaly determined.

The Division of Building Reserrch steadily extended its work, completing a detailed study of the properties of asphalt singles, continuing basic studies of the movement of moisture in solid materials and making good progress in research into the strength of floating sheets of ice. In the Division of Mechanical Engineering the aerodynamics section is examining the possibilities of vertical take-off and landing, while studies with jet aircraft at high subsonic and transonic speeds demonstrated several methods of improving the characteristics of airframes and engines. Work continued in the hydraulics laboratory to provide design data for navigation locks and river improvements for several St. Lawrence Seaway projects. In gas dynamics the major design effort was on a gas turbine unit for railway traction, while much effort was given to the development of rotor de-icing equipment for helicopters, and to problems of dynamics and dynamic loading of structures.
Very substantial economy in operation and maintenance of buoy lights has resulted through application of transistor circuits developed by the Radio and Electrical Engineering Division. A transmitter, power supply and antenna are under development which will survive a crash and automatically radiate a signal that can be detected by searching aircraft. A novel circuit has been developed in which a quartz crystal is used to stabilize two variable-frequency oscillators. In high-voltage research successive stages of electric-spark formation in air were photographed by using an image converter as a very high-speed optical shutter, and growth of spark diameter and brightness were correlated with various theories of spark formation. The hazard of sparks created by falling steel objects received much attention, but no ignition was obtained with drops as grest as $80 \mathrm{ft}$. Tests on the St. Lawrence Seaway showed that radar shore installations would be advantageous in scheduling the arrival of vessels at lock entrances so that traffic may be handled more efficiently. A survey conducted for the Government of Newfoundland showed that a very-high-frequency radiotelephony system would provide adequate communications for vessels of the 'long liner' fishing fleets.

\section{FIELD STUDIES COUNCIL}

TN 1957 there was again an increase in the number 1 of students attending the various field centres of the Field Studies Council and at most of them the pressure of attendances was kept up steadily throughout the season. This is brought out in the annual report (pp. $68+8$ plates. London: Field Studies Council, 1958) for 1956-57, which shows that the number of students attending in 1951 had almost doubled in 1957. The new centre at Preston Montford opened in March 1957, and by the close of the season it had just managed to top the thousand mark in terms of student-weeks. Once again, the increase in numbers has been general, but in accordanoe with the Council's policy there has been some development of attendances from secondary modern schools, particularly at Preston Montford, where special 'countryside' courses have been provided.

The pressure at peak times of the year has continued, this being particularly pronounced in the spring, when most of the centres could fill their vacancies two and three times over. Although the opening of the new centre has gone a little way to redress the position, it, in turn, became rapidly over-subseribed at the peak of the spring period.

At the older centres the 'valleys' have been largely filled up, but it would still help if schools could arrange wherever possible to send their first-year sixth-formers at times of year which did not conflict with the peak period of bookings in April.

The Council finds itself still having to face the problem of rising costs, and this, coupled with the prospect of the Ministry of Education's grant being gradually withdrawn after 1958-59, has caused the Committe to raise again the basic charge.

The opening of any further centres is almost entirely dependent on the question of whether adequate initial capital and future support can be forthcoming from outside sources. It seems possible that at some future date an additional centre in the south-west of England might be feasible and, if this should materialize, it would mean that the Council as a whole would have a very satisfactory geographical spread over the counties of England and Wales.

\section{SCIENTIFIC EDUCATION IN THE UNITED STATES}

N his budget message to Congress on January 13,
President Eisenhower emphasized the need to
expand the United States efforts in scientific research
and said that this is a task for private industry,
research foundations and educational institutions as
well as for the Government. Supplementary appro-
priations for 1958 would be requested for the National
Advisory Committee for Aeronautics and the National
Science Foundation as well as for the Department of
Defence. For 1959 new programmes to promote
education in science are being recommended and
basic research activities are being generally expanded.
Total Government expenditure on equipment of the
United States forces and those of its allies, on nuclear energy and on scientific research and education will be 21,000 million dollars in 1958 and 21,600 million dollars in 1959 compared with 20,500 million dollars in 1957. This budget, President Eisenhower added, reflects co-ordinated plans for strengthening defence, greater pooling of scientific resources and freer exchange of technological information, as well as eloser economic co-operation. Expenditure by the U.S. Atomic Energy Commission will increase to 2,550 million dollars in 1959 , compared with 2,300 million dollars in 1958 and 1,990 million dollars in 1957. For technical assistance, 164 million dollars are requested for 1959 and appropriations of 140 million dollars are proposed for the National Science 